\title{
The effect of insulin and insulin-like growth factors on hippocampus- and amygdala-dependent long-term memory formation
}

\author{
Sarah A. Stern, ${ }^{1,2}$ Dillon Y. Chen, ${ }^{2}$ and Cristina M. Alberini ${ }^{1}$ \\ ${ }^{1}$ Center for Neural Science, New York University, New York, New York 10003, USA; ${ }^{2}$ Graduate School of Biological Sciences, Icahn \\ School of Medicine at Mount Sinai, New York, New York 10029, USA
}

\begin{abstract}
Recent work has reported that the insulin-like growth factor 2 (IGF2) promotes memory enhancement. Furthermore, impaired insulin or IGF1 functions have been suggested to play a role in the pathogenesis of neurodegeneration and cognitive impairments, hence implicating the insulin/IGF system as an important target for cognitive enhancement and/or the development of novel treatments against cognitive disorders. Here, we tested the effect of intracerebral injections of IGFI, IGF2, or insulin on memory consolidation and persistence in rats. We found that a bilateral injection of insulin into the dorsal hippocampus transiently enhances hippocampal-dependent memory and an injection of IGF1 has no effect. None of the three peptides injected into the amygdala affected memories critically engaging this region. Together with previous data on IGF2, these results indicate that IGF2 produces the most potent and persistent effect as a memory enhancer on hippocampal-dependent memories. We suggest that the memory-enhancing effects of insulin and IGF2 are likely mediated by distinct mechanisms.
\end{abstract}

The insulin-like growth factors 1 and 2 (IGF1 and IGF2) are polypeptides that have high sequence similarity to insulin. IGFs, together with insulin, their related cell surface receptors, binding proteins, and degrading enzymes are part of a complex system known for its important role in growth and development (Jones and Clemmons 1995). Recent work, however, has implicated IGFs and insulin in cognitive functions, and a number of studies have suggested their potential effect on cognitive enhancement and as compounds that may ameliorate cognitive disorders and even neurodegeneration (de la Monte 2013). A better understanding of the effects, target brain areas, and mechanisms of IGFs and insulin on cognition may help to develop novel translational approaches for the treatment of cognitive disorders. Notably, both insulin and IGF1 peptides are being tested in clinical trials as treatments for Alzheimer's disease (AD) and autism, respectively (Schiöth et al. 2012; Freiherr et al. 2013; Khwaja et al. 2014).

Previous work in our laboratory has shown that IGF2 expression is up-regulated following learning under the functional control of the transcription factor CCAAT enhancer binding protein $\beta$ $(\mathrm{C} / \mathrm{EBP} \beta)$, and that its functional role is necessary for inhibitory avoidance (IA) memory consolidation. Moreover, hippocampal injections of recombinant IGF2 significantly enhance IA and contextual fear conditioning (CFC) memory, whereas amygdala injections have no effect (Chen et al. 2011). Hippocampal injections of IGF2 are also known to enhance the extinction of CFC in mice (Agis-Balboa et al. 2011) and systemic injections of IGF2 in mice significantly increase different forms of short- and long-term memory (Stern et al. 2014).

Studies in rodents showed that an intracerebroventricular injection of insulin immediately after inhibitory avoidance (IA) training leads to memory enhancement $24 \mathrm{~h}$ after training (Park et al. 2000; Babri et al. 2007) and that intracerebroventricular or hippocampal injection of insulin enhances spatial working memory and water maze memory (Moosavi et al. 2006; Haj-ali et al.

Corresponding author: ca60@nyu.edu

Article is online at http://www.learnmem.org/cgi/doi/10.1101/Im.029348.112.
2009; McNay et al. 2010). To our knowledge, there is no report thus far on the role of IGF1 on memory retention and performance; however, beneficial effects of exercise and recovery from brain insult or neurodegeneration have been shown to involve IGF1, possibly acting through neurogenesis (Aberg et al. 2000; Carro et al. 2001). Furthermore, a truncated IGF1 peptide was reported to partially rescue Rett syndrome-like phenotypes in MeCP2 knockout mice (Tropea et al. 2009).

To determine whether IGFs and insulin are effective cognitive enhancers and/or may efficaciously combat the progression of cognitive impairments, it is important to establish the effects of IGFs and insulin on memory consolidation and persistence. Because memories exist in different forms and critically involve different neural circuitry (Squire and Wixted 2011), it is important that the effect of cognitive enhancers be established on different types of memory. Brain lesions and stimulations have indicated that the hippocampus is critically involved in cognitive, spatial, contextual, and explicit memories, whereas the amygdala is critical in emotional conditioning (Berman et al. 1978; Phillips and LeDoux 1992). Learning paradigms such as IA, CFC, or cued fear conditioning (e.g., auditory fear conditioning, AFC) in animal models have been instrumental for establishing the differential roles of the hippocampus or amygdala in the consolidation and storage of different forms of memories, and have provided useful tools for identifying hippocampal and amygdala contributions to distinct memory systems (Berman et al. 1978; Phillips and Ledoux 1992). While IA and CFC model hippocampal-dependent memories in which amygdala plays a modulatory role, cued (e.g., auditory) fear conditioning is a model for amygdala-dependent memories in which the amygdala exerts a more critical role in consolidation and storage (LeDoux 2000; McIntyre et al. 2003;

\footnotetext{
(C) 2014 Stern et al. This article is distributed exclusively by Cold Spring Harbor Laboratory Press for the first 12 months after the full-issue publication date (see http://learnmem.cshlp.org/site/misc/terms.xhtml). After 12 months, it is available under a Creative Commons License (Attribution-NonCommercial 4.0 International), as described at http://creativecommons.org/licenses/by$\mathrm{nc} / 4.0 /$.
} 
Kim and Jung 2006). In this study, we tested the effect of a bilateral injection of IGF1, IGF2, or insulin into the dorsal hippocampus or amygdala on hippocampal-dependent and/or amygdala-dependent memories.

\section{Results}

\section{IGF2 injected into the amygdala has no effect} on amygdala-dependent memories

Because IGF2 is required in the rat hippocampus for IA memory consolidation and dorsal hippocampal injections of IGF2 lead to a significant memory enhancement of contextual memories including IA and CFC, but not of the amygdala-dependent memory AFC (Chen et al. 2011), here we tested the effect of a bilateral intrabasolateral amygdala (BLA) injection of IGF2 immediately after AFC on memory retention and persistence in rats. As depicted in Figure $1 \mathrm{~A}$, no difference between IGF2 and vehicle-injected rats was found at test given $24 \mathrm{~h}$ after training $(P=0.46$, Student's $t$-test). The efficacy of all batches of IGF2 was guaranteed by the manufacturer (R\&D) and measured as the activity in a serum-free cell proliferation assay using MCF7 human breast cancer calls according to Karey and Sirbasku (1988). In addition, we were able to confirm the IGF2 effect on memory, because IGF2 taken from the same batch injected bilaterally into the hippocampus of rats immediately after IA testing (reactivation), given $1 \mathrm{~d}$ after training, produced memory enhancement $24 \mathrm{~h}$ later $(P<0.0001$, Student's $t$-test; Fig. 1B). We concluded that IGF2 significantly and persistently enhances hippocampal-dependent memories when injected into the hippocampus, but has no effect on amygdaladependent memories and/or amygdala mechanisms.

\section{Insulin injected into the hippocampus transiently enhances hippocampal- but not amygdala-dependent memories}

We next tested the effect of a bilateral injection of insulin into the dorsal hippocampus of rats immediately after IA or within-subject $\mathrm{CFC} / \mathrm{AFC}$ training. The animals were tested $24 \mathrm{~h}$ (Test 1 ) and $7 \mathrm{~d}$ later (Test 2).
A
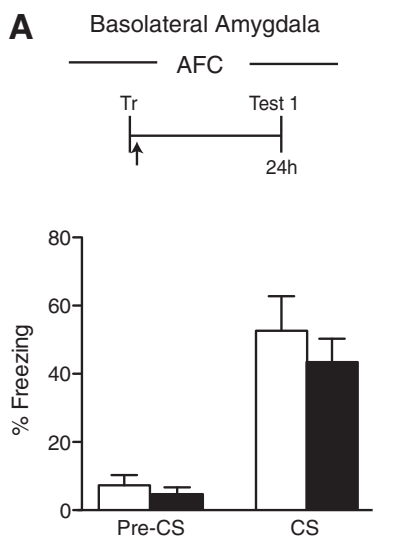

Vehicle
B
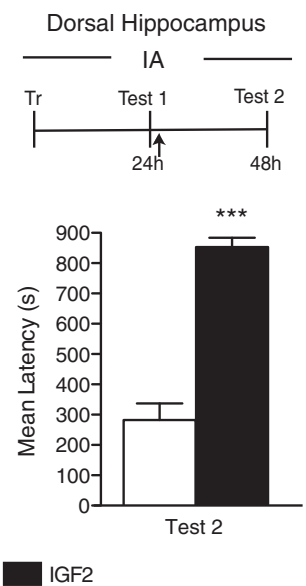

Figure 1. IGF2 injected into the BLA has no effect on AFC memory. Experimental schedule is shown above the figure. (A) AFC memory retention is expressed as the percent freezing \pm SEM of rats given a bilateral amygdala injection (arrow) of vehicle or IGF2 immediately after AFC training (Tr). Retention was tested at $24 \mathrm{~h}$ (Test 1$)$ after training $(n=9)$. (B) IA memory retention is expressed as the mean latency \pm SEM (in seconds) of rats given a bilateral hippocampal injection (arrow) of vehicle or IGF2 immediately after testing (Test 1 ) given $24 \mathrm{~h}$ after IA training ( $\mathrm{Tr}$ ). Retention was tested $24 \mathrm{~h}$ (Test 2$)$ later $(n=5)$. (***) $P<0.001$.
In agreement with previous reports (Park et al. 2000; Babri et al. 2007), we found that a two-way ANOVA followed by a Bonferroni post hoc test revealed a significant effect of insulin, compared with vehicle, in enhancing IA memory at a test given $24 \mathrm{~h}$ after IA training (significant treatment effect: $F_{(1,24)}=5.73$, $P=0.02$; no test effect: $F_{(1,24)}=0.82, P=0.37$; no interaction effect: $F_{(1,24)}=2.56, P=0.12$; post hoc: Veh vs. insulin [Test 1]: $P<0.05)$. However, when memory was retested $7 \mathrm{~d}$ after training, the effect did not persist, indicating that insulin-mediated memory enhancement is transient (Fig. 2A).

To exclude an effect of Test 1 , groups of rats were bilaterally injected into the hippocampus with either vehicle or insulin immediately after IA training and tested only at $7 \mathrm{~d}$ after training. No difference in memory retention was found between the two groups, confirming that insulin has no effect on long-term memory retention ( $P=0.76$, Student's $t$-test, Fig. $2 B)$.

Insulin, bilaterally injected into the dorsal hippocampus immediately after within-subject CFC/AFC conditioning (see Materials and Methods), led to a trend toward an increase in CFC retention $24 \mathrm{~h}$ after training, without affecting AFC memory 48 $\mathrm{h}$ after training (Fig. 2C). At Test 2, $6 \mathrm{~d}$ later, the effect of insulin was no longer observed (CFC, no treatment effect: $F_{(1,24)}=0.88$, $P=0.37$; no test effect: $F_{(1,24)}=19.34, P=0.0002$; significant interaction effect: $F_{(1,24)}=4.90, P=0.04$; post hoc: Test 1 versus Test 2 [insulin]: $P<0.001$, two-way ANOVA with Bonferroni post hoc test; Fig. 2C, left); (AFC, no treatment effect: $F_{(1,24)}=2.17$, $P=0.15$; no test effect: $F_{(1,24)}=1.49, P=0.23$; no interaction effect: $F_{(1,24)}=0.02, P=0.90$; two-way ANOVA; Fig. 2C, right). Pretone freezing of AFC was minimal and similar for both treatment groups at both Test 1 and Test 2, indicating that insulin per se did not change freezing levels.

To exclude an interaction of multiple testing and withinsubject memory-competition effects, we further tested the effect of insulin on independently conducted CFC and AFC.

Rats were trained in CFC with one unsignaled footshock (see Materials and Methods), injected immediately after with vehicle or insulin, and tested $24 \mathrm{~h}$ (Test 1 ) and $7 \mathrm{~d}$ (Test 2) later. As shown in Figure 2D, compared with vehicle-injected rats, insulin-injected rats had a significantly enhanced retention at Test 1 . However, this enhancement was no longer observed at Test 2, confirming that the insulin-induced memory enhancement is transient (significant treatment effect: $F_{(1,28)}=9.97, P=0.004$; significant test effect: $F_{(1,28)}=4.59, P=0.04$; no interaction effect: $F_{(1,28)}=$ $2.59, P=0.12$; post hoc: Veh vs. insulin [Test 1]: $P<0.01$, Test 1 vs. Test 2 [insulin]: $P<0.05$; two-way ANOVA with Bonferroni post hoc test).

Rats trained in AFC with one tone-shock pairing and bilaterally injected immediately after training into the dorsal hippocampus with either insulin or vehicle showed comparable retention at both $24 \mathrm{~h}$ (Test 1 ) or $7 \mathrm{~d}$ (Test 2) tests, as well as minimal and similar pretone freezing (no treatment effect: $F_{(1,18)}=0.04, P=0.85$; no test effect: $F_{(1,18)}=1.86, P=0.19$; no interaction effect: $F_{(1,18)}=0.15, P=0.70$; two-way ANOVA; Fig. 2E).

We concluded that insulin produces an enhancement of hippocampal-dependent memories but this enhancement is transient. Furthermore, insulin, like IGF2, has no effect on amygdaladependent memory.

\section{Insulin injected into the amygdala has no effect on hippocampal- or amygdala-dependent memories}

We next tested the effect of insulin injected into the BLA on IA or AFC. Groups of rats were trained in either IA or AFC and bilaterally injected immediately after training with vehicle or insulin into the BLA. The effect was tested at $24 \mathrm{~h}$ (Test 1 ) and $7 \mathrm{~d}$ (Test 2 ) after training. As shown in Figure 3A,B, a trend toward memory 
Dorsal Hippocampus
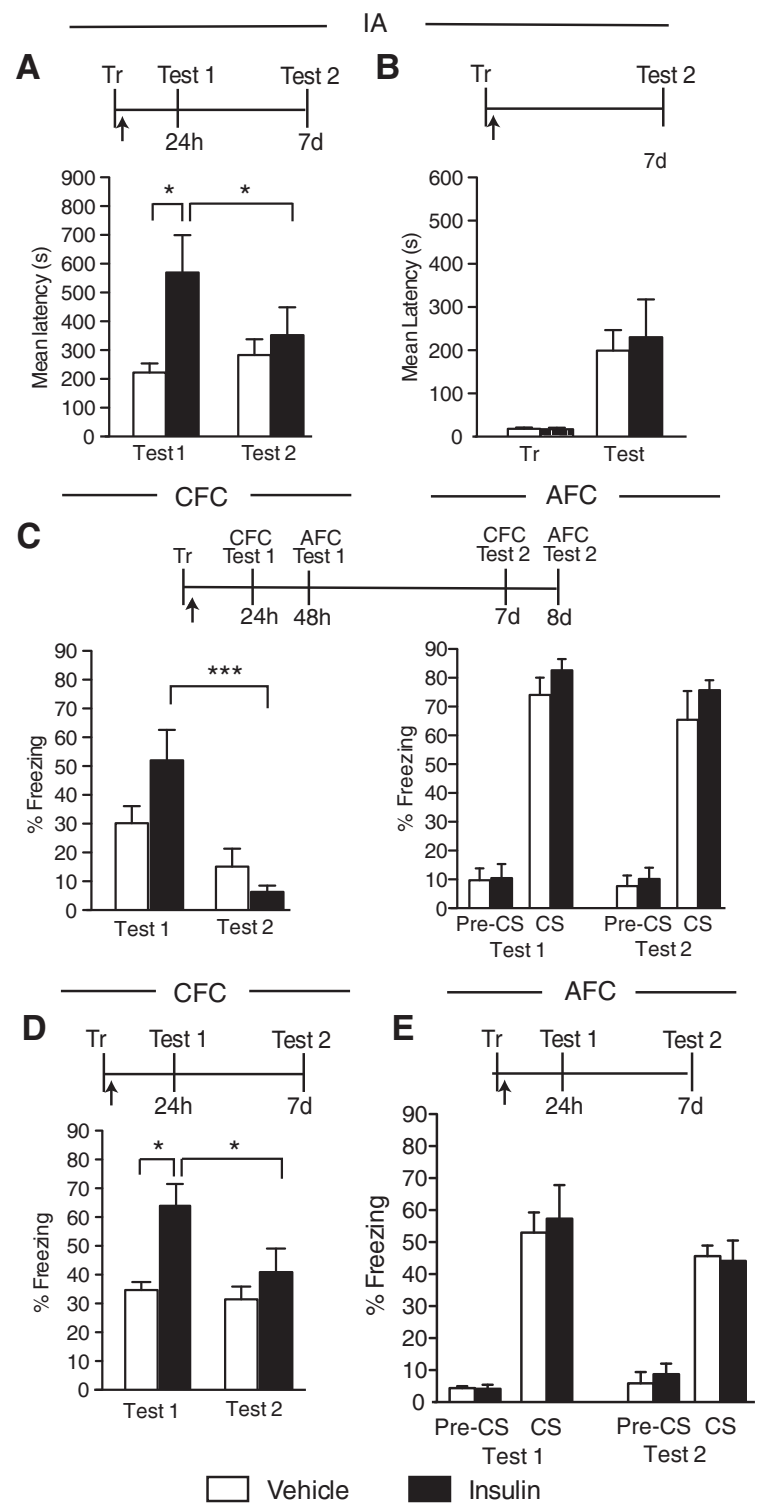

Figure 2. Insulin transiently enhances hippocampal-dependent memories. Experimental schedules are shown above figures. (A) IA memory retention is expressed as the mean latency \pm SEM (in seconds) of rats given a bilateral hippocampal injection (arrow) of vehicle or insulin immediately after IA training (Tr) and tested $24 \mathrm{~h}$ (Test 1) and $7 \mathrm{~d}$ (Test 2) later $(n=7)$. (B) IA memory retention is expressed as the mean latency \pm SEM (in seconds) of rats given a bilateral hippocampal injection (arrow) of vehicle or insulin immediately after IA training (Tr). Retention was tested $7 \mathrm{~d}$ (Test) later $(n=5-6)$. (C) CFC and AFC memories retention are expressed as the mean percent freezing \pm SEM of rats given a bilateral hippocampal injection (arrow) of vehicle or insulin immediately after within-subject CFC/AFC training (Tr). CFC (left) was tested $24 \mathrm{~h}$ (Test 1, CFC) and $7 \mathrm{~d}$ (Test 2, CFC) after training. AFC (right) was tested $48 \mathrm{~h}$ (Test $1, \mathrm{AFC})$ and $8 \mathrm{~d}$ (Test 2, AFC) after training $(n=7)$. Freezing was scored before the onset of the tone (pre-CS) and during the tone presentation (CS). (D) CFC memory retention is expressed as the mean percent freezing \pm SEM of rats given a bilateral hippocampal injection (arrow) of vehicle or insulin immediately after CFC training (Tr) and tested $24 \mathrm{~h}$ (Test 1$)$ and $7 \mathrm{~d}$ (Test 2) later $(n=8)$. (E) AFC memory retention is expressed as the mean percent freezing \pm SEM of rats given a bilateral hippocampal injection (arrow) of vehicle or insulin immediately after AFC training (Tr). Retention was tested $24 \mathrm{~h}$ (Test 1) and $7 \mathrm{~d}$ (Test 2) later $(n=5-6)$. Freezing was scored before the onset of the tone (pre-CS) and during the tone presentation (CS). $\left(^{*}\right) P<0.05$; ( $\left(^{* *}\right) P<0.001$. enhancement at both Test 1 and Test 2 was seen with both tasks; however, the enhancement did not reach statistical significance (IA, no treatment effect: $F_{(1,30)}=1.49, P=0.23$; no test effect: $F_{(1,30)}=0.43, P=0.52$; no interaction effect: $F_{(1,30)}=0.07, P=$ 0.80; two-way ANOVA, Fig. 3A); (AFC, no treatment effect: $F_{(1,20)}=0.64, P=0.43$; no test effect: $F_{(1,20)}=0.05, P=0.83$; no interaction effect: $F_{(1,20)}=0.01, P=0.91$; two-way ANOVA, Fig. $3 \mathrm{~B})$. To exclude that the limited effect was due to a low dosage, we also tested a higher dose of insulin into the BLA: again found no effect, and actually the higher dose blunted any trend toward enhancement of AFC (no treatment effect: $F_{(1,21)}=0.01, P=0.92$; no test effect: $F_{(1,21)}=0.11, P=0.74$; no interaction effect: $F_{(1,21)}=0.002, P=0.96$; two-way ANOVA, Fig. 3C). With both doses, pretone freezing during AFC testing was minimal and similar in both treatment groups.

Hence BLA injections of insulin have no effect on hippocampal- or amygdala-dependent memories.

\section{IGF1 injected into the hippocampus does not affect hippocampal- or amygdala-dependent memories}

We have previously found that a bilateral hippocampal injection of IGF1 has no effect on IA memory retention (Chen et al. 2011). In this study, we tested the effect of IGF1 on CFC and AFC combined and as separate protocols. The efficacy of the IGF1 used was guaranteed by the manufacturer: The IGF1 activity was measured in a serum-free cell proliferation assay using MCF7 human breast cancer cells (Karey and Sirbasku 1988). Unfortunately, because to our knowledge no effects of IGF1 have been thus far reported on memory enhancement, we could not use a positive control based on memory tasks.

Groups of rats were trained in the within-subject CFC/AFC paradigm, injected immediately after training into the dorsal hippocampus, and tested $24 \mathrm{~h}$ later for CFC memory (CFC Test 1 ) and $48 \mathrm{~h}$ later for AFC memory (AFC Test 1 ). The animals were then retested in both tasks (Test 2) $6 \mathrm{~d}$ after Test 1 . No difference in memory retention was found between vehicle- and IGF1-injected rats at either test (CFC, no treatment effect: $F_{(1,24)}=0.52, P=0.4776$; significant test effect: $F_{(1,24)}=8.62, P=0.01$; no interaction effect: $\left.F_{(1,30)}=0.18, P=0.68\right) ;\left(\right.$ AFC, no treatment effect: $F_{(1,22)}=1.36$, $P=0.26$; significant test effect: $F_{(1,22)}=0.95, P=0.34$; no interaction effect: $F_{(1,22)}=0.06, P=0.82$; two-way ANOVA, Fig. $4 \mathrm{~A}$ ).

Similar data were obtained when the CFC and AFC were conducted between subjects (Fig. 4B,C): IGF1 and vehicle-injected rats showed similar memory at both Test 1 ( $24 \mathrm{~h}$ after training) and Test 2 (7 d after training); (CFC, no treatment effect: $F_{(1,20)}=0.12, P=$ 0.73 ; no test effect: $F_{(1,20)}=2.81, P=0.11$; no interaction effect: $F_{(1,20)}=1.10, P=0.31$; two-way ANOVA, Fig. $\left.4 \mathrm{~B}\right)$; (AFC, no treatment effect: $F_{(1,18)}=1.73, P=0.20$; no test effect: $F_{(1,18)}=0.99$, $P=0.33$; no interaction effect: $F_{(1,18)}=0.00003, P=0.996$; twoway ANOVA, Fig. 4C).

We concluded that a bilateral hippocampal injection of IGF1, unlike that of IGF2 or insulin, has no effect on hippocampal- or amygdala-dependent memories.

\section{IGF1 injected into the amygdala has no effect on hippocampal- or amygdala-dependent memories}

We finally tested the effect of a bilateral BLA injection of IGF1 on IA or AFC. Groups of rats received a bilateral injection of vehicle or IGF1 into the BLA immediately after IA or AFC training and were tested $24 \mathrm{~h}$ (Test 1) and $7 \mathrm{~d}$ (Test 2) after training. No difference in memory retention between the groups was found on either IA (no treatment effect: $F_{(1,17)}=0.02, P=0.90$; no test effect: $F_{(1,17)}=0.05, P=0.83$; no interaction effect: $F_{(1,17)}=0.02$, $P=0.88$; two-way ANOVA; Fig. $5 \mathrm{~A}$ ) or AFC (no treatment effect: 
Basolateral Amygdala
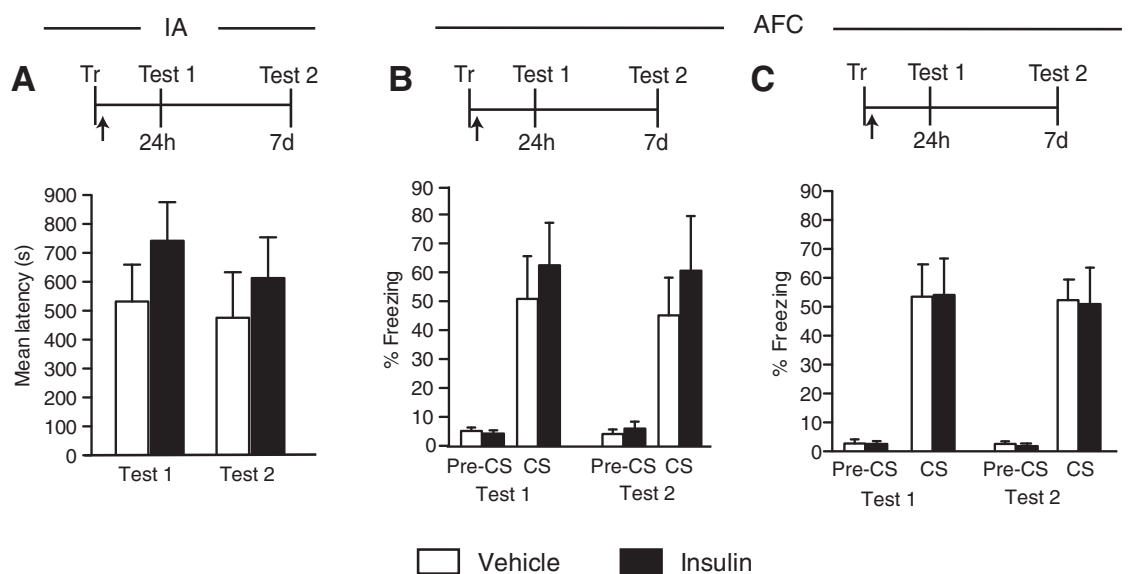

Figure 3. Insulin does not affect IA or AFC memory when injected into BLA. Experimental schedules are shown above figures. (A) IA memory retention is expressed as the mean latency \pm SEM (in seconds) of rats given a bilateral BLA injection (arrow) of vehicle or insulin immediately after IA training (Tr). Retention was tested $24 \mathrm{~h}$ (Test 1$)$ and $7 \mathrm{~d}$ (Test 2$)$ later $(n=8-9)$. (B,C) AFC memory retention is expressed as the mean percent freezing \pm SEM of rats given a bilateral BLA injection (arrow) of vehicle or a low dose $(B, n=5-8)$ or high dose $(C, n=8)$ of insulin immediately after AFC training ( $\operatorname{Tr})$. Retention was tested $24 \mathrm{~h}$ (Test 1 ) and $7 \mathrm{~d}$ (Test 2) later. Freezing was scored before the onset of the tone (pre-CS) and during the tone presentation (CS).

$F_{(1,19)}=0.30, P=0.59$; no test effect: $F_{(1,19)}=0.02, P=0.88$; no interaction effect: $F_{(1,19)}=0.07, P=0.79$; two-way ANOVA; Fig. $5 \mathrm{~B})$. Pre-tone freezing during AFC testing was minimal and similar for both treatment groups. We concluded that IGF1 in the BLA does not affect retention of amygdala- or hippocampal-dependent memories.

\section{Discussion}

There is an urgent need for the identification of effective cognitive enhancers, which may help the development of novel treatments for neuropsychiatric disorders involving memory impairments. Our recent findings in rodents that IGF2, injected into the hippocampus or systemically, can significantly and persistently enhance the retention of hippocampal-dependent memories (Chen et al. 2011; Stern et al. 2014) led us to investigate and compare the role of IGF2, IGF1, or insulin injected intracerebrally in either the hippocampus or amygdala on hippocampal- and amygdaladependent tasks. Here we report that whereas a single injection of IGF1 has no effects on any of the memories investigated, regardless of the brain region in which it was injected into, insulin leads, as also suggested by previous studies (Park et al. 2000; Babri et al. 2007), to memory enhancement when injected into the hippocampus. However, we found the effect of insulin to be transient. The transient effect of insulin was seen only when the hippocampus was targeted, whereas an injection into the BLA produced no effect, regardless of multiple doses tested. In contrast, IGF2 emerged as the most potent memory enhancer when injected into the hippocampus and on hippocampal-dependent memories, as a single injection immediately after training led to significant and long-lasting effects (see Chen et al. 2011). Like insulin, IGF2 had no effect when delivered into the BLA or on amygdaladependent memories. We conclude that IGF2 is the most powerful cognitive enhancer among the three related peptides, and given the distinct temporal effects, we suggest that the memory-enhancing effects of IGF2 and insulin involve distinct mechanisms.

Previous studies have reported that intraventricular or dorsal hippocampal injections of insulin in rats immediately after IA or water maze training, or before water maze retrieval, increase memory retention or retrieval $24 \mathrm{~h}$ after training (Park et al. 2000; Moosavi et al. 2006; Babri et al. 2007; Haj-ali et al. 2009). However, these studies did not test memory retention at later time-points. Furthermore, the conclusion that insulin had an enhancing effect on memory has been controversial: Different doses of insulin and times of administration in relationship to training, as well as systemic administrations, have produced impairing effects on memory (Clayson 1971; Schwarzberg et al. 1989; Kopf and Baratti 1996, 1999; Kopf et al. 1998; Moosavi et al. 2006). To our knowledge, the only study that reported the effect of insulin on memory persistence was carried out with systemic treatments, and showed memory impairment at 7 and $30 \mathrm{~d}$ after training (Kopf and Baratti 1996). However, in this regard, one should take into account that the negative effect of systemically administered insulin on memory retention might likely be due to metabolic effect of hyperinsulinemia, which was not investigated in these studies.

It is possible that the transient effect of insulin we have observed is due to the single injection and that prolonged treatments of brain-delivered insulin may lead to more persistent memory enhancements. In line with this hypothesis, more persistent memory-enhancing effects of insulin, and specifically on memories relying on hippocampal functions such as declarative memories, have been reported in human with prolonged intranasal administrations, whereas nondeclarative memories, such as wordstem priming, were found to be unaffected (Benedict et al. 2008). This similarity between the effect on human memories and that on rat hippocampal-dependent, but not on amygdala-dependent, memories is intriguing and suggests that not all types of memories or memory systems are affected by insulin.

Why is insulin-mediated memory enhancement transient, whereas IGF2-mediated memory enhancement is persistent? Addressing this question requires further investigation of their mechanisms of action. We speculate that the effect of insulin on memory may result from metabolic changes occurring in both neurons and astrocytes. This hypothesis is based on the observations that although insulin receptor immunoreactivity has been described to be more abundant on neurons, astrocytes are known to express both insulin receptor B (IR-B) subunits and the proteins of the insulin signaling pathway. Furthermore, applying insulin to astrocytic cultures can increase glucose incorporation into glycogen (Heni et al. 2011). Finally, in the periphery as well as in the hippocampus, insulin leads to translocation of the neuronal insulin-sensitive glucose transporter type 4 (GLUT4) to the plasma membrane (Grillo et al. 2009), which further leads to increased glucose uptake into neurons, thus also implicating a metabolic mechanism of action. In agreement with this metabolic hypothesis, McNay et al. (2010) showed that hippocampal delivery of insulin enhances spatial memory, decreases glucose extracellular levels, and increases lactate levels in the hippocampal extracellular space, indicating an increase in local glycolytic metabolism (McNay et al. 2010). Similar to insulin, glucose itself seems to produce a transient memory enhancement (Suzuki et al. 2011), suggesting that indeed, insulin may enhance memory primarily via glucose metabolism regulation. 
Dorsal Hippocampus

A
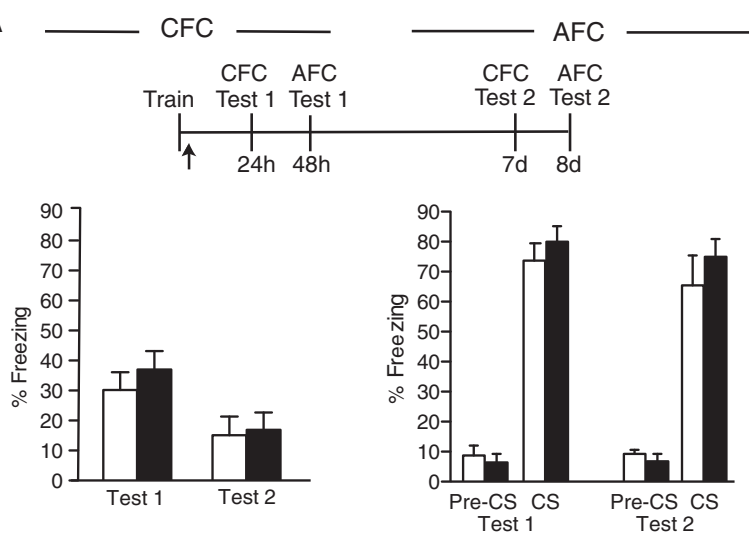

B

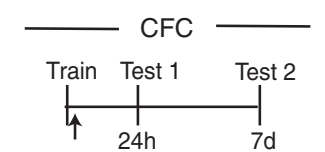

C
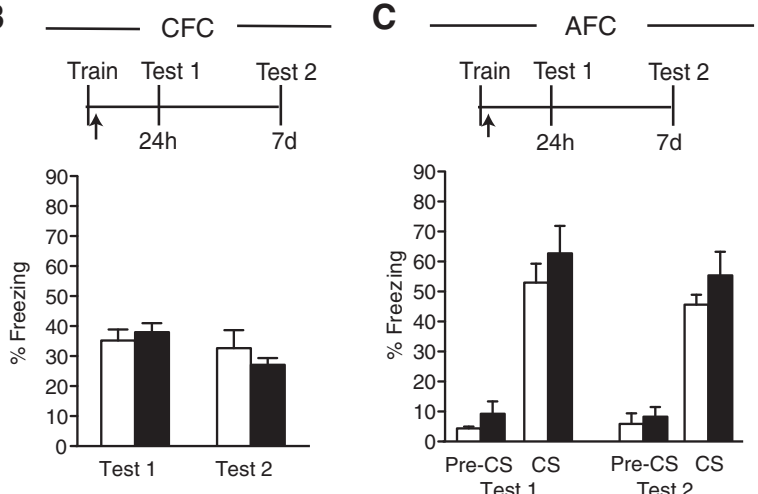

Vehicle

IGF1

Figure 4. IGF1 injected into hippocampus has no effect on hippocampal- or amygdala-dependent memories. Experimental schedules are shown above figures. (A) CFC and AFC memory retentions are expressed as the mean percent freezing \pm SEM of rats given a bilateral hippocampal injection (arrow) of vehicle or IGF1 immediately after within-subject CFC/AFC training (Tr). CFC (left) was tested $24 \mathrm{~h}$ (Test 1 , CFC) and $7 \mathrm{~d}$ (Test 2, CFC) after training. AFC (right) was tested $48 \mathrm{~h}$ (Test 1, AFC) and $8 \mathrm{~d}$ (Test 2, AFC) after training. Freezing was scored before the onset of the tone (pre-CS) and during the tone presentation (CS) $(n=6-7)$. (B) CFC memory retention is expressed as the mean percent freezing \pm SEM of rats given a bilateral hippocampal injection (arrow) of vehicle or IGF1 immediately after CFC training (Tr). Retention was tested $24 \mathrm{~h}$ (Test 1$)$ and $7 \mathrm{~d}$ (Test 2 ) later $(n=6)$. (C) AFC memory retention is expressed as the mean perecent freezing \pm SEM of rats given a bilateral hippocampal injection (arrow) of vehicle or IGF1 immediately after AFC training (Tr). Retention was tested $24 \mathrm{~h}$ (Test 1 ) and 7 d (Test 2) later. Freezing was scored before the onset of the tone (pre-CS) and during the tone presentation (CS) $(n=5-6)$.

Concerning the mechanisms of action of IGF2, our previous studies in rats targeting the hippocampus showed that the IGF2-dependent effect on memory requires IGF2 receptors but not IGF1 receptors, and is mediated by Arc and GSK3 $\beta$ (Chen et al. 2011). Furthermore, IGF2-mediated memory enhancement correlates with an increase in the concentration of synaptic GluA1 subunits of AMPA receptors (Chen et al. 2011). Our studies with systemically administered IGF2 in mice revealed that the subcutaneous injection of IGF2 enhances Arc and Zif268 levels in the hippocampus and leads to a trend toward an increase of Zif 268 in the prefrontal cortex, suggesting that IGF2 promotes activity or plasticity on these regions (Stern et al. 2014). These data further

the conclusion that IGF2 affects mainly the hippocampal-cortical systems and acts on plasticity mechanisms. Given that insulin does not bind to IGF2 receptors (Jones and Clemmons 1995) and the different temporal profile of IGF2 and insulin effects, we propose that the memory-enhancing effects mediated by IGF2 and insulin occur through distinct mechanisms. We suggest that while insulin acts mainly through glucose metabolism, the IGF2-mediated memory-enhancing mechanisms target activity or plasticity mechanisms, and perhaps in addition to, as suggested by previous literature, acetylcholine modulation (Napoli et al. 2008; Cline et al. 2012; Kita et al. 2013), GABA modulation (Amritraj et al. 2010), and vesicle- and/or receptor trafficking (Alberini and Chen 2012).

In agreement with our findings of the lack of effects of IGF1 on memory enhancement, there is no report to our knowledge indicating that IGF1 enhances memory in healthy conditions. However, several studies in both humans and rodent models have shown a rescuing effect of IGF1, as well as insulin or IGF2, on cognitive functions in pathological conditions, particularly in mild cognitive impairment or Alzheimer's disease (AD) with insulin (Born et al. 2002; Reger et al. 2006, 2008; Sims-Robinson et al. 2010), and on cerebrovascular alterations, aging and AD with IGF1 (Liu et al. 2001, 2004; Carro et al. 2002; Craft et al. 2012; Fernandez and Torres-Aleman 2012; Torres Aleman 2012; Johansson et al. 2013; Trueba-Saiz et al. 2013).

IGF2, like IGF1 and insulin, may also be beneficial in rescuing cognitive impairments in diseases, as it can promote synapse formation and spine maturation in the mouse brain (Schmeisser et al. 2012), and perhaps through the IGF1receptor (IGF1R), may affect neurogenesis and consequently contribute to hippocampaldependent spatial learning and memory (Bracko et al. 2012; Ouchi et al. 2013). Like IGF1 and insulin, the expression of IGF2 and IGF2 receptor (IGF2R) have been found altered in the brain AD patients (Kar et al. 2006) and IGF2 ameliorates AD-related deficits in an AD mouse model (Mellott et al. 2014).

Basolateral Amygdala

A
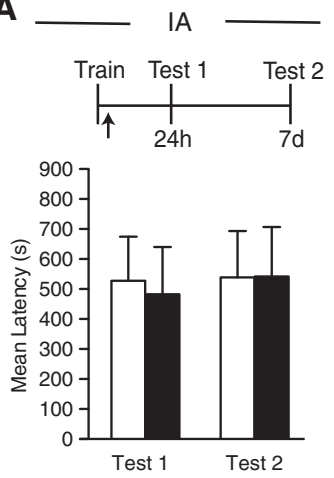

Vehicle
B
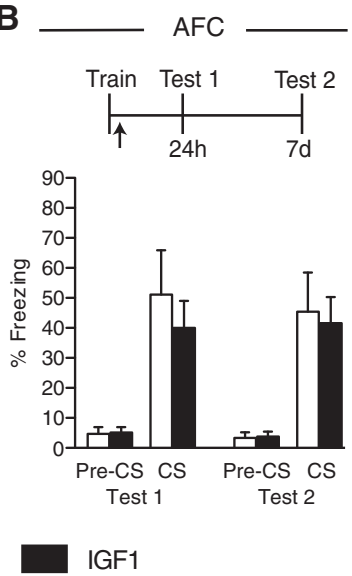

Figure 5. IGF1 injected into the BLA has no effect on hippocampalor amygdala-dependent memories. Experimental schedules are shown above figures. (A) IA memory retention is expressed as the mean latency \pm SEM (in seconds) of rats given a bilateral BLA injection (arrow) of vehicle or IGF1 immediately after IA training (Tr). Retention was tested $24 \mathrm{~h}$ (Test 1$)$ and $7 \mathrm{~d}$ (Test 2$)$ later $(n=5-8)$. (B) AFC memory retention is expressed as the mean percent freezing \pm SEM of rats given a bilateral BLA injection (arrow) of vehicle or IGF1 immediately after training (Tr). Retention was tested $24 \mathrm{~h}$ (Test 1 ) and $7 \mathrm{~d}$ (Test 2) later. Freezing was scored before the onset of the tone (pre-CS) and during the tone presentation (CS) $(n=4-6)$. 
We conclude that IGF2 has the strongest effect among the IGFs/insulin peptides in promoting enhancement and persistence of memories relying on hippocampal-cortical networks. Thus, IGF2 represents an important potential target for developing cognitive enhancers in normal or pathological conditions.

\section{Materials and Methods}

\section{Animals}

Adult male Long-Evans rats weighing between 200 and $250 \mathrm{~g}$ at the beginning of the experiment were used. Animals were individually housed and maintained on a 12 -h light-dark cycle. Experiments were performed during the light cycle. All rats were allowed ad libitum access to food and water and were handled for $3 \mathrm{~min} / \mathrm{d}$ for $5 \mathrm{~d}$ prior to any experimental manipulations. All protocols complied with the National Institutes of Health Guide for the Care and Use of Laboratory Animals and were approved by the New York University and the Mount Sinai School of Medicine Animal Welfare Committees.

\section{Cannulae implants}

Hippocampal and amygdala injections were conducted as described previously (Taubenfeld et al. 2001; Tronel and Alberini 2007). Rats were anesthetized with ketamine (65 mg/kg, i.p.) and xylazine $(7.5 \mathrm{mg} / \mathrm{kg}$, i.p.), and stainless steel guide cannulae (22-gauge for hippocampus, 28-gauge for basolateral amygdala) were stereotactically implanted to bilaterally target either the hippocampus $(4.0 \mathrm{~mm}$ posterior to the bregma; $2.6 \mathrm{~mm}$ lateral from midline; and $2.0 \mathrm{~mm}$ ventral from the skull surface) or BLA (2.8 $\mathrm{mm}$ posterior to bregma; $5.3 \mathrm{~mm}$ lateral from midline; and 6.25 $\mathrm{mm}$ ventral from the skull surface). The rats were returned to their home cages and allowed to recover from surgery for $7 \mathrm{~d}$ before behavioral experiments. Immediately after training, rats received bilateral injections of compounds as specified. All injections are indicated in the figures by an arrow in the experimental schedule. Hippocampal injections were delivered in a volume of $1 \mu \mathrm{L}$ per side and used a 28 -gauge needle that extended $1.5 \mathrm{~mm}$ beyond the tip of the guide cannula. BLA injections were delivered in a volume of $0.5 \mu \mathrm{L}$ per side and used a 33-gauge needle that extended $1.5 \mathrm{~mm}$ beyond the top of the guide cannula. Guide cannulae were connected via polyethylene tubing to Hamilton syringes. All infusions were delivered at a rate of $0.333 \mu \mathrm{L} / \mathrm{min}$ using an infusion pump. The injection needle was left in place for $2 \mathrm{~min}$ after the injection to allow complete dispersion of the solution.

To verify proper placement of cannula implants, at the end of the behavioral experiments, rats were perfused with $4 \%$ paraformaldehyde in PBS and brains were postfixed in the same solution. Forty micrometer coronal sections were cut through the relevant brain region and examined under a light microscope. Figure 6 shows the representative areas targeted by the stereotactic injections performed in this study. Animals with incorrect cannula placement were discarded from the study. None of the animals injected into the hippocampus were excluded; $4 \%$ of the animals injected into the amygdala were excluded for incorrect cannula placement.

\section{Inhibitory avoidance (IA)}

Inhibitory avoidance was carried out as previously described (Taubenfeld et al. 2001). The IA chamber (Med Associates. Inc.) consisted of a rectangular Perspex box divided into a safe compartment and a shock compartment. The safe compartment was white and illuminated by a light fixture fastened to the cage lid. The shock compartment was dark and made of black Perspex. Footshocks were delivered to the grid floor of the shock chamber via a constant current scrambler circuit. The two compartments were separated by an automatically operated sliding door. The apparatus was located in a sound-attenuated, nonilluminated room. During training sessions, each rat was placed in the safe compartment facing away from the door. After $10 \mathrm{sec}$, the door separating the compartments was automatically opened, allowing the rat access to the shock compartment. The door closed $1 \mathrm{sec}$ after the rat entered the shock compartment, and a 2-sec 0.6-mA footshock was delivered. Latency to enter the shock compartment was taken in seconds as a measure of acquisition. The rat was then returned to its home cage and tested for memory retention at the designated time-point(s). Retention tests were performed by placing the rat back in the safe compartment and measuring its latency to enter the shock compartment. Footshocks were not administered on the retention tests, and testing was terminated at $900 \mathrm{sec}$. Training and testing procedures were performed blind to treatments.

\section{Contextual and auditory fear conditioning (CFC and AFC)}

Rats were conditioned in a fear-conditioning chamber, which consisted of a rectangular Plexiglass box $(30.5 \times 24.1 \times 21.0 \mathrm{~cm})$ with a metal grid floor (Model ENV-008, Med Associates). The withinsubjects CFC/AFC protocol was carried out as described previously (Chen et al. 2011): All rats were preexposed to this chamber for 5 min. The next day, rats were placed in the CFC chamber for 120 sec and then presented with $30 \mathrm{sec}$ of the auditory cue consisting of a $5-\mathrm{kHz} 75-\mathrm{dB}$ tone that coterminated with a $0.6-\mathrm{mA} 2$-sec footshock. One hundred twenty seconds after the first footshock, another 30-sec auditory cue was presented that also coterminated with another 0.6-mA 2-sec footshock. Rats were returned to their home cage $120 \mathrm{sec}$ after the second footshock. At the designated time-point (e.g., $24 \mathrm{~h}$ after training), rats were placed back in the CFC chamber and their freezing levels were recorded for $5 \mathrm{~min}$ and scored. Twenty-four hours after the CFC test, rats were placed in a different context (the illuminated IA box) for 120 sec before being presented with three 30 -sec auditory cues. The three 30 -sec auditory cues were separated by 120 sec.

In some experiments, $\mathrm{CFC}$ and $\mathrm{AFC}$ were performed in independent groups of rats (between-subjects). In these cases, for CFC training, rats were placed in the chamber for $120 \mathrm{sec}$ and then presented with an unsignaled 0.6-mA footshock for $2 \mathrm{sec}$. One minute later, rats were removed. Testing occurred at designated time-points in the same chamber, wherein the rat was placed for 3 min. For AFC training, rats were placed in the chamber for 120 sec and then presented with 30 sec of the auditory cue consisting of a $5-\mathrm{kHz} 75-\mathrm{dB}$ tone that coterminated with a $0.6-\mathrm{mA} 2-\mathrm{sec}$
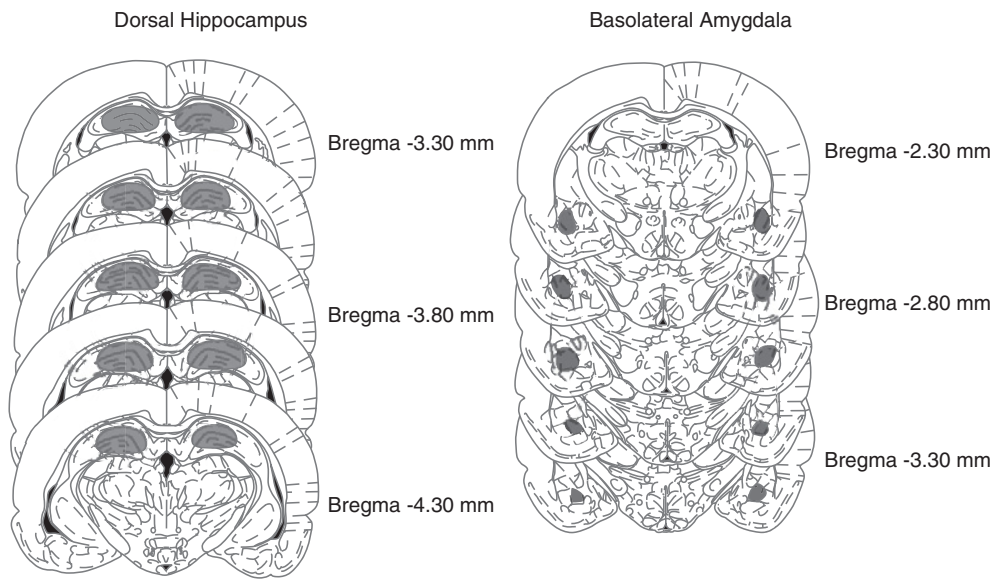

Figure 6. Schematic representations of injection sites into the dorsal hippocampus and BLA at the indicated rostrocaudal planes. The numbers represent the coordinates from bregma (in millimeters) according to Paxinos and Watson (2007). Injections sites were contained within the gray-shaded areas. (Reprinted from Paxinos and Watson 2007 with permission from Elsevier (C) 2007.) 
footshock. Rats were returned to their home cage 1 min after the footshock. Testing occurred at designated time-points by placing rats into a distinct context (the illuminated IA box) for $120 \mathrm{sec}$ before being presented with three 30 -sec tones separated by $120 \mathrm{sec}$. Testing ended $60 \mathrm{sec}$ after the last tone presentation. No footshock was delivered during testing. All experiments were video recorded, and freezing, defined as lack of movement except for breathing, was scored by an experimenter blind to the treatment conditions. For the AFC experiments, freezing was averaged over the three tone presentations.

\section{Drug injections}

Recombinant mouse IGF1 and IGF2 were purchased from R\&D, dissolved in $0.1 \%$ bovine serum albumin (BSA) in $1 \times \mathrm{PBS}$, and injected at a dose of $0.25 \mu \mathrm{g} /$ injection per side (Chen et al. 2011). Recombinant human insulin was purchased from Sigma Aldrich, dissolved in $1 \times$ saline, and injected at a dose of $2 \mathrm{mU}$ or $8 \mathrm{mU} / \mathrm{in}$ jection per side. At the lower dose $(2 \mathrm{mU} / \mu \mathrm{L})$, insulin had been shown to enhance memory when injected into the hippocampus (Babri et al. 2007). All experiments were repeated multiple times with independent groups of animals and independent batches of IGF1, IGF2, and insulin.

\section{Statistical analyses}

Two-way analysis of variance (ANOVA) followed by the Bonferroni post hoc test, or Student's t-test was used for statistical analyses.

\section{Acknowledgments}

This work was supported by grants from the US National Institute of Mental Health (R01/R37-MH065635 to C.M.A., F31-MH090636 to S.S., and F31-MH816213 to D.Y.C.). The authors declare no competing financial interests. We thank Aisha Hassan and the staffs of the UAWC at NYU and at the Icahn School of Medicine at Mount Sinai for technical support.

\section{References}

Aberg MA, Aberg ND, Hedbacker H, Oscarsson J, Eriksson PS. 2000. Peripheral infusion of IGF-I selectively induces neurogenesis in the adult rat hippocampus. J Neurosci 20: 2896-2903.

Agis-Balboa RC, Arcos-Diaz D, Wittnam J, Govindarajan N, Blom K, Burkhardt S, Haladyniak U, Agbemenyah HY, Zovoilis A, Salinas-Riester G, et al. 2011. A hippocampal insulin-growth factor 2 pathway regulates the extinction of fear memories. EMBO J 30: 4071-4083.

Alberini CM, Chen DY. 2012. Memory enhancement: consolidation, reconsolidation and insulin-like growth factor 2. Trends Neurosci 35: $274-283$.

Amritraj A, Rauw G, Baker GB, Kar S. 2010. Leu27 insulin-like growth factor-II, an insulin-like growth factor-II analog, attenuates depolarization-evoked GABA release from adult rat hippocampal and cortical slices. Neuroscience 170: $722-730$.

Babri S, Badie HG, Khamenei S, Seyedlar MO. 2007. Intrahippocampal insulin improves memory in a passive-avoidance task in male Wistar rats. Brain Cogn 64: 86-91.

Benedict C, Kern W, Schultes B, Born J, Hallschmid M. 2008. Differential sensitivity of men and women to anorexigenic and memory-improving effects of intranasal insulin. J Clin Endocrinol Metab 93: 1339-1344.

Berman RF, Kesner RP, Partlow LM. 1978. Passive avoidance impairment in rats following cycloheximide injection into the amygdala. Brain Res 158: $171-188$

Born J, Lange T, Kern W, McGregor GP, Bickel U, Fehm HL. 2002. Sniffing neuropeptides: a transnasal approach to the human brain. Nat Neurosci 5: $514-516$.

Bracko O, Singer T, Aigner S, Knobloch M, Winner B, Ray J, Clemenson GD Jr, Suh H, Couillard-Despres S, Aigner L, et al. 2012. Gene expression profiling of neural stem cells and their neuronal progeny reveals IGF2 as a regulator of adult hippocampal neurogenesis. J Neurosci 32: 3376-3387.

Carro E, Trejo JL, Busiguina S, Torres-Aleman I. 2001. Circulating insulin-like growth factor I mediates the protective effects of physical exercise against brain insults of different etiology and anatomy. $J$ Neurosci 21: $5678-5684$.
Carro E, Trejo JL, Gomez-Isla T, LeRoith D, Torres-Aleman I. 2002. Serum insulin-like growth factor I regulates brain amyloid- $\beta$ levels. Nat Med 8: $1390-1397$.

Chen DY, Stern SA, Garcia-Osta A, Saunier-Rebori B, Pollonini G, Bambah-Mukku D, Blitzer RD, Alberini CM. 2011. A critical role for IGF-II in memory consolidation and enhancement. Nature 469: $491-497$.

Clayson SJ. 1971. Effect of hypoglycemia on T-maze learning in rats. Phys Ther 51: 991-999.

Cline BH, Steinbusch HW, Malin D, Revishchin AV, Pavlova GV, Cespuglio R, Cespuglio R, Strekalova T. 2012. The neuronal insulin sensitizer dicholine succinate reduces stress-induced depressive traits and memory deficit: possible role of insulin-like growth factor 2. BMC Neurosci 13: 110.

Craft S, Baker LD, Montine TJ, Minoshima S, Watson GS, Claxton A, Arbuckle M, Callaghan M, Tsai E, Plymate SR, et al. 2012. Intranasal insulin therapy for Alzheimer disease and amnestic mild cognitive impairment: a pilot clinical trial. Arch Neurol 69: 29-38.

de la Monte SM. 2013. Intranasal insulin therapy for cognitive impairment and neurodegeneration: current state of the art. Expert Opin Drug Deliv 10: $1699-1709$.

Fernandez AM, Torres-Aleman I. 2012. The many faces of insulin-like peptide signalling in the brain. Nat Rev Neurosci 13: 225-239.

Freiherr J, Hallschmid M, Frey WH II, Brunner YF, Chapman CD, Holscher C, Craft S, De Felice FG, Benedict C. 2013. Intranasal insulin as a treatment for Alzheimer's disease: a review of basic research and clinical evidence. CNS Drugs 27: 505-514.

Grillo CA, Piroli GG, Hendry RM, Reagan LP. 2009. Insulin-stimulated translocation of GLUT4 to the plasma membrane in rat hippocampus is PI3-kinase dependent. Brain Res 1296: 35-45.

Haj-ali V, Mohaddes G, Babri SH. 2009. Intracerebroventricular insulin improves spatial learning and memory in male Wistar rats. Behav Neurosci 123: 1309-1314.

Heni M, Hennige AM, Peter A, Siegel-Axel D, Ordelheide AM, Krebs N, Machicao F, Fritsche A, Häring HU, Staiger H. 2011. Insulin promotes glycogen storage and cell proliferation in primary human astrocytes. PLoS One 6: e21594.

Johansson P, Aberg D, Johansson JO, Mattsson N, Hansson O, Ahren B, Isgaard J, Ảberg ND, Blennow K, Zetterberg H, et al. 2013. Serum but not cerebrospinal fluid levels of insulin-like growth factor-I (IGF-I) and IGF-binding protein-3 (IGFBP-3) are increased in Alzheimer's disease. Psychoneuroendocrinology 38: 1729-1737.

Jones JI, Clemmons DR. 1995. Insulin-like growth factors and their binding proteins: biological actions. Endocr Rev 16: 3-34.

Kar S, Poirier J, Guevara J, Dea D, Hawkes C, Robitaille Y, Quirion R. 2006 Cellular distribution of insulin-like growth factor-II mannose-6-phosphate receptor in normal human brain and its alteration in Alzheimer's disease pathology. Neurobiol Aging 27: 199-210.

Karey KP, Sirbasku DA. 1988. Differential responsiveness of human breast cancer cell lines MCF-7 and T47D to growth factors and $17 \beta$-estradiol. Cancer Res. 48: 4083-4092.

Khwaja OS, Ho E, Barnes KV, O'Leary HM, Pereira LM, Finkelstein Y, Nelson CA III, Vogel-Farley V, DeGregorio G, Holm IA, et al. 2014. Safety, pharmacokinetics, and preliminary assessment of efficacy of mecasermin (recombinant human IGF-1) for the treatment of Rett syndrome. Proc Natl Acad Sci 111: 4596-4601.

Kim JJ, Jung MW. 2006. Neural circuits and mechanisms involved in Pavlovian fear conditioning: a critical review. Neurosci Biobehav Rev 30: $188-202$.

Kita Y, Ago Y, Takano E, Fukada A, Takuma K, Matsuda T. 2013. Galantamine increases hippocampal insulin-like growth factor 2 expression via $\alpha 7$ nicotinic acetylcholine receptors in mice. Psychopharmacology 225: 543-551.

Kopf SR, Baratti CM. 1996. Memory modulation by post-training glucose or insulin remains evident at long retention intervals. Neurobiol Learn Mem 65: 189-191.

Kopf SR, Baratti CM. 1999. Effects of posttraining administration of insulin on retention of a habituation response in mice: participation of a central cholinergic mechanism. Neurobiol Learn Mem 71: 50-61.

Kopf SR, Boccia MM, Baratti CM. 1998. AF-DX 116, a presynaptic muscarinic receptor antagonist, potentiates the effects of glucose and reverses the effects of insulin on memory. Neurobiol Learn Mem 70: 305-313.

LeDoux JE. 2000. Emotion circuits in the brain. Annu Rev Neurosci 23: $155-184$.

Liu XF, Fawcett JR, Thorne RG, DeFor TA, Frey WH II. 2001. Intranasal administration of insulin-like growth factor-I bypasses the blood-brain barrier and protects against focal cerebral ischemic damage. J Neurol Sci 187: $91-97$.

Liu XF, Fawcett JR, Hanson LR, Frey WH II. 2004. The window of opportunity for treatment of focal cerebral ischemic damage with 
noninvasive intranasal insulin-like growth factor-I in rats. J Stroke Cerebrovasc Dis 13: 16-23.

McIntyre CK, Power AE, Roozendaal B, McGaugh JL. 2003. Role of the basolateral amygdala in memory consolidation. Ann N Y Acad Sci 985: 273-293.

McNay EC, Ong CT, McCrimmon RJ, Cresswell J, Bogan JS, Sherwin RS. 2010. Hippocampal memory processes are modulated by insulin and high-fat-induced insulin resistance. Neurobiol Learn Mem 93: 546-553.

Mellott TJ, Pender SM, Burke RM, Langley EA, Blusztajn JK. 2014. IGF2 ameliorates amyloidosis, increases cholinergic marker expression and raises BMP9 and neurotrophin levels in the hippocampus of the APPswePS1dE9 Alzheimer's disease model mice. PLoS One 9: e94287.

Moosavi M, Naghdi N, Maghsoudi N, Zahedi Asl S. 2006. The effect of intrahippocampal insulin microinjection on spatial learning and memory. Horm Behav 50: 748-752.

Napoli I, Blusztajn JK, Mellott TJ. 2008. Prenatal choline supplementation in rats increases the expression of IGF2 and its receptor IGF2R and enhances IGF2-induced acetylcholine release in hippocampus and frontal cortex. Brain Res 1237: 124-135.

Ouchi Y, Banno Y, Shimizu Y, Ando S, Hasegawa H, Adachi K, Iwamoto T. 2013. Reduced adult hippocampal neurogenesis and working memory deficits in the Dgcr8-deficient mouse model of 22q11.2 deletion-associated schizophrenia can be rescued by IGF2. J Neurosci 33: $9408-9419$.

Park CR, Seeley RJ, Craft S, Woods SC. 2000. Intracerebroventricular insulin enhances memory in a passive-avoidance task. Physiol Behav 68: 509-514.

Paxinos G, Watson C. 2007. The rat brain in stereotaxic coordinates. Elsevier Academic Press, New York.

Phillips RG, LeDoux JE. 1992. Differential contribution of amygdala and hippocampus to cued and contextual fear conditioning. Behav Neurosci 106: $274-285$.

Reger MA, Watson GS, Frey WH II, Baker LD, Cholerton B, Keeling ML, Belongia DA, Fishel MA, Plymate SR, Schellenberg GD, et al. 2006. Effects of intranasal insulin on cognition in memory-impaired older adults: modulation by APOE genotype. Neurobiol Aging 27: 451-458.

Reger MA, Watson GS, Green PS, Wilkinson CW, Baker LD, Cholerton B, Fishel MA, Plymate SR, Cherrier MM, Schellenberg GD, et al. 2008. Intranasal insulin improves cognition and modulates $\beta$-amyloid in early AD. Neurology 70: $440-448$.
Schmeisser MJ, Baumann B, Johannsen S, Vindedal GF, Jensen V, Hvalby OC, Belongia DA, Fishel MA, Plymate SR, Schellenberg GD, et al. 2012. ІкB kinase/nuclear factor $\kappa$ B-dependent insulin-like growth factor 2 (Igf2) expression regulates synapse formation and spine maturation via Igf2 receptor signaling. J Neurosci 32: 5688-5703.

Schiöth HB, Craft S, Brooks SJ, Frey WH II, Benedict C. 2012. Brain insulin signaling and Alzheimer's disease: current evidence and future directions. Mol Neurobiol 46: 4-10.

Schwarzberg H, Bernstein HG, Reiser M, Gunther O. 1989. Intracerebroventricular administration of insulin attenuates retrieval of a passive avoidance response in rats. Neuropeptides 13: 79-81.

Sims-Robinson C, Kim B, Rosko A, Feldman EL. 2010. How does diabetes accelerate Alzheimer disease pathology? Nat Rev Neurol 6: 551-559.

Squire LR, Wixted JT. 2011. The cognitive neuroscience of human memory since H.M. Annu Rev Neurosci 34: 259-288.

Stern SA, Kohtz AS, Pollonini G, Alberini CM. 2014. Enhancement of memories by systemic administration of insulin-like growth factor II. Neuropsychopharmacology 39: 2179-2190.

Suzuki A, Stern SA, Bozdagi O, Huntley GW, Walker RH, Magistretti PJ, Alberini CM. 2011. Astrocyte-neuron lactate transport is required for long-term memory formation. Cell 144: 810-823.

Taubenfeld SM, Milekic MH, Monti B, Alberini CM. 2001. The consolidation of new but not reactivated memory requires hippocampal C/EBPß. Nat Neurosci 4: 813-818.

Torres Aleman I. 2012. Insulin-like growth factor-1 and central neurodegenerative diseases. Endocrinol Metab Clin North Am 41: $395-408$, vii.

Tronel S, Alberini CM. 2007. Persistent disruption of a traumatic memory by postretrieval inactivation of glucocorticoid receptors in the amygdala. Biol Psychiatry 62: 33-39.

Tropea D, Giacometti E, Wilson NR, Beard C, McCurry C, Fu DD, Flannery R, Jaenisch R, Sur M. 2009. Partial reversal of Rett syndrome-like symptoms in MeCP2 mutant mice. Proc Natl Acad Sci 106: 2029-2034.

Trueba-Saiz A, Cavada C, Fernandez AM, Leon T, Gonzalez DA, Fortea Ormaechea J, Lleó A, Del Ser T, Nuñez A, Torres-Aleman I. 2013. Loss of serum IGF-I input to the brain as an early biomarker of disease onset in Alzheimer mice. Transl Psychiatry 3: e330.

Received May 19, 2014; accepted in revised form August 1, 2014. 


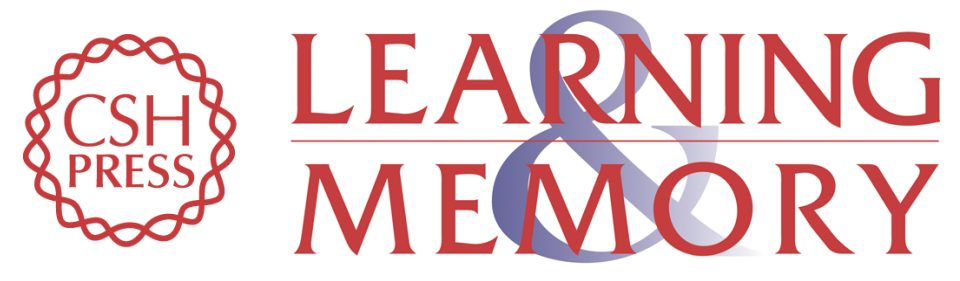

\title{
The effect of insulin and insulin-like growth factors on hippocampus- and amygdala-dependent long-term memory formation
}

\author{
Sarah A. Stern, Dillon Y. Chen and Cristina M. Alberini
}

Learn. Mem. 2014, 21:

Access the most recent version at doi:10.1101//m.029348.112

References This article cites 56 articles, 9 of which can be accessed free at: http://learnmem.cshlp.org/content/21/10/556.full.html\#ref-list-1

Creative This article is distributed exclusively by Cold Spring Harbor Laboratory Press for the Commons first 12 months after the full-issue publication date (see License http://learnmem.cshlp.org/site/misc/terms.xhtml). After 12 months, it is available under a Creative Commons License (Attribution-NonCommercial 4.0 International), as described at http://creativecommons.org/licenses/by-nc/4.0/.

Email Alerting Receive free email alerts when new articles cite this article - sign up in the box at the Service top right corner of the article or click here. 